\title{
REGIONAL LIFESTYLE SEGMENTATION IN THE WESTERN BALKANS
}

Melika Husić-Mehmedović, Muris Čičić, Emir Agić *

\section{Abstract}

With this paper the authors aim not only to investigate the lifestyle specifics of the Western Balkan market, but also to define common lifestyle segments for the entire region. The question addressed in this research is whether current political issues and economic differences have led to dissimilar ways of living, or whether cultural similarities have prevailed and lifestyles can be defined accordingly.

Based on the research conducted using six underlying factors, three lifestyle clusters are identified. Analysis shows that there are three almost identical lifestyles for Bosnia and Herzegovina, Croatia, Serbia and Slovenia, and they are applicable to the entire region. These findings have significant managerial implications, as potential investors can apply identical marketing strategies to target the approximately 20 million consumers in the region.

Keywords: Lifestyle, psychographic, regional segmentation

JEL: $M 39, Z 13$

\section{INTRODUCTION}

Contemporary marketing and consumer behavior theory and practice use lifestyle studies for segmenting the market and understanding lifestyle similarities and differences. The efficiency of geographic and demographic segmentation has been challenged as it fails to capture the personality nuances (e.g. psychographics) that separate customers by meaningful brand experiences and relational behaviors (Barry and Weinstein 2009). Thus, lifestyle positioning has become an increasingly common approach among managers, especially in commodity categories in which functional differences are difficult to maintain (Chernev, Hamilton and Gal 2011). To many managers, lifestyle branding seems to offer a way of breaking free of the cutthroat competition within a category by
* Melika Husić-Mehmedović, PhD

School of Economics and Business, University of Sarajevo melika.husic@efsa.unsa.ba

\section{Muris Čičić, PhD}

School of Economics and Business, University of Sarajevo muris.cicic@efsa.unsa.ba

\section{Emir Agić, PhD}

School of Economics and Business, University of Sarajevo emir.agic@efsa.unsa.ba 
connecting with consumers on a more personal level. Lifestyle researchers using the values paradigm draw from a short list of universal antecedents to human action to explain consumption patterns (Holt 1997).

This paper is focused on the Western Balkan countries of Slovenia, Croatia, Serbia and Bosnia and Herzegovina. The main research problem defined by the authors is that these countries are rather small markets per se for potential investors, yet together they comprise a market of approximately 20 million customers. Regional segmentation based on lifestyle might introduce common segments and thus result in a standardized market approach among potential investors. The focal research question is whether we can profile the same lifestyle clusters at the regional level and consequently treat the Western Balkans as a common market for investors.

The observed countries were once republics within the former Yugoslavia. Approximately 20 years ago, the dissolution of Yugoslavia resulted in different socio-economic development within each newlyestablished country. Even within a region with many similarities in terms of language, culture and history, many differences arose during this transitional period. Therefore, the authors wanted to research whether current trends led to dissimilar ways of living, or whether previous similarities had prevailed and lifestyles could be defined accordingly.

\section{LIFESTYLE SEGMENTATION}

From the start lifestyle has been a broadly defined social term, combining all of the general similarities one can observe among people, including drives, emotions, cultural experiences, or life plans (Adler 1929). In a psychological sense Levy (1963) finds that lifestyle is an expression of values, describing the roles people play in life and how they think those roles should be fulfilled. They reveal both real and ideal lifestyles. Similarly, Havighurst and deVries (1969) see lifestyle as a syndrome of role activities with a dominant central theme, which is behaviorally visible, a syndrome that represents a group. As such, it is crucial to point out the differences in attitudes between groups, while keeping in mind the similarities in behavioral patterns within the same group. Overall, researchers agree that in a social, psychological and economic sense lifestyle is a combination of psychological and social characteristics. As a result, lifestyle-based segmentation is also called psychographics (Demby 1974).

The first definition of lifestyle from a marketing perspective comes from Feldman and Thielbar (1972).
They stated that lifestyle is a group phenomenon that combines many aspects of life. It implies a central life interest and differs according to sociologically relevant variables. Wind and Green (1974) explain the way in which products and services are consumed within a lifestyle, which brings this term into correlation with consumer behavior based on which scholars have developed definitions from the consumer point of view. Sobel (1983) defines lifestyle as a set of expansive, observable behaviors. Similarly, Featherstone (1987) states that lifestyle finds its meaning in reference to the distinctive style of life of specific status groups. Instead of inducting psychological traits from an amalgam of measures in the manner of the personality approach, values research pursues a more deductive project in which people are sorted into lifestyle groups on the basis of their rankings or weightings of a priori values.

From its origins in consumer behavior research, psychographics or lifestyle has become a well-accepted segmentation method, particularly in consumer markets (Barry and Weinstein 2009). Customer profiling has advanced to a point where entire product launch campaigns are designed around complex personality profiles.

Further, individuality in certain socio-demographic surroundings influences lifestyle. While some authors think that lifestyle is individual and specific for everyone (Adler 1929; Murphy 1974), the majority support the theory that it is a group phenomenon based on the same or similar ways that people behave (Feldman and Thielbar 1972; Havinghurst and De Vries 1969; Zablocki and Kantor 1976; Miedema 1989). The consensus of opinion was that lifestyle represents a combination of individual characteristics and the surroundings in which a person lives. Both the object signification and personality/values approaches assume that lifestyles are shared consumption patterns (Holt 1997). Therefore, Schutz, Baird and Hawke (1979) define lifestyle as the orientation to self, others and society that each individual develops and follows. Such an orientation derives from personal beliefs based on cultural context and the psychosocial milieu related to the stage of an individual's life. Finally, Ruiz (1990) thinks that not only personal peculiarities have to do with an individual's beliefs, values or norms of daily behavior, but also the way in which each person conforms to the group, class or global society to which he or she belongs. Those findings contribute to consumer behavior, because researchers used lifestyle to define groups/segments with the same or similar ways of living, since they will most likely have similar consumption patterns. Consumers make both 
conscious and unconscious decisions based on their current lifestyle when it comes to their needs and attitudes, and their choice of product or brand. Lifestyle is changeable, which accordingly leads to changes in consumption patterns. Further, family lifestyle will determine individual lifestyle; however, individuality will be maintained (Bootsma, Camstra, de Feijter and Mol 1993). Hence lifestyles not only express collectivities; they also serve to reproduce these relationships. Lifestyles lead to associating with similarly socialized people and distancing from people from different backgrounds, and this process of interactional elective affinity reproduces the social conditions on which collectivities are based (Holt 1997).

Psychographic segmentation divides consumers into different groups depending on their lifestyle and personalities. Consumers in the same demographic group can express different individual profiles. Such approaches are backed by a broad literature showing that consumers prefer brands positioned around the identities they possess (e.g., Escalas and Bettman 2005). The foundations of the literature emphasize fit: consumers seek brands that fit their identity and respond favorably to messages that best communicate fit (Reed et al. 2012). Consumer identity research has focused on the vast potential of achieving a fit between brand and consumer identity (StokburgerSauer et al. 2012).

However, contemporary studies (Bhattacharjee, Berger, Menon 2014) argue that explicit identitymarketing messages may reduce purchase likelihood. Consumers perceive such explicit identity marketing as a threat to free identity expression and avoid brands they would otherwise prefer in order to restore their sense of agency. Consumers are thought to respond more favorably to messages that invoke their identity and show how it fits with a given brand (Reed et al. 2012). There are also some negative implications of lifestyle segmentation for companies as well. Chernev, Hamilton and Gal (2011) argue that managers may be trading fierce within-category functional competition for fierce across-category symbolic competition, whereby all self-expressive brands could end up competing with one another. Thus, by switching from functional branding to lifestyle branding, managers might be setting themselves up for even stronger competition for a share of a consumer's identity.

Reseachers were generally focused on identification of the trends which influence consumers such as their life, work or leisure, while analyzing lifesyle (Anderson and Golden 1984). Consumers use certain products to accomplish and/or maintain their relationships with others (Lin 2002). Therefore, whether in the leisure activities market (Green et al. 2006), banking (Peltier et al. 2002), apparel marketing (RichardsSturman 1977), museum marketing (Todd, Lawson 2001) or B2B marketing (Barry and Weinstein 2009), it is important to know the lifestyle of our target market, so that we can offer them suitable recreational or cultural activities (Pronay, Hetesi, Veres 2009).

In the past decades, different scales were developed for measuring consumer values and attitudes. Some of the best known value based methods are VALS (Values and Lifestyle) (Reece 1989; Shih 1986; Hawkins, Best and Coney 1993), and Kahle's (1983) LOV (List of Values).

\section{METHODOLOGY}

This survey uses the VALS methodology, which was originally developed by consumer futurist Arnold Mitchell in 1969. The main dimensions of the segmentation framework are primary motivation and resources. An individual's primary motivation determines what in particular constitutes the meaningful core that governs an individual's activities. One of three primary motivations inspires consumers: ideals (guided by knowledge and principles), achievement (demonstrate success to their peers), and self-expression (desire for social or physical activity, variety, and risk). Resources that play a critical role in buying decisions are a person's energy, self-confidence, intellectualism, novelty seeking, innovativeness, impulsiveness, leadership, and vanity (SRI Consulting Business Intelligence 2006).

The survey for the purpose of this study was conducted in the following countries in the Western Balkans: Bosnia and Herzegovina, Croatia, Serbia and Slovenia. The survey aimed to define and compare individual lifestyles, as well as to define the shared lifestyle segments in this region. The questionnaire for Bosnia and Herzegovina, Croatia and Serbia were distributed in the same language, while a translation into Slovenian was provided for respondents from Slovenia.

The planned convenience based sample was two hundred respondents from each country and ended up with 762 respondents. Table 1 shows sample characteristics. 
Table 1: Sample characteristics

\begin{tabular}{|l|r|}
\hline Characteristics & Ratio (\%) \\
\hline Country & \\
\hline Bosnia and Herzegovina & 27,8 \\
Croatia & 26,4 \\
Serbia & 21,3 \\
Slovenia & 24,5 \\
\hline Gender & \\
\hline Male & 47,9 \\
Female & 52,1 \\
\hline Education & \\
\hline Elementary school & 0,4 \\
High school & 21,6 \\
College degree & 67,4 \\
Post-graduate education & 10,6 \\
\hline Annual financial income & \\
\hline Below 5.000 $€$ & 16,3 \\
$5.000-9.999 €$ & 18,9 \\
$10.000-14.999 €$ & 15,1 \\
15.000 - 19.999 $€$ & 15,0 \\
20.000 - 24.999 $€$ & 9,0 \\
25.000 - $29.999 €$ & 8,1 \\
30.000 - $49.999 €$ & 14,6 \\
$50.000 €$ and above & 3,0 \\
\hline
\end{tabular}

The rationale for analyzing the markets of these four countries is that lifestyle segments were never defined within them, and moreover each market per $s e$ is not lucrative enough for potential investors. Due to the fact that these countries were all part of the former Yugoslavia, the question addressed in this research is whether recent political issues and economic differences have led to a dissimilar way of living, or whether cultural similarities prevailed such that lifestyles could be defined accordingly.

\section{ANALYSIS AND DISCUSSION}

In order to identify factors in the VALS scale, explorative factor analysis (EFA) was conducted. EFA defined a seven-factor solution. Based on the seven-factor solution, a confirmative factor analysis (CFA) was conducted for the entire sample followed by a multiple group analysis (MGA). The main objective of CFA and MGA was to eliminate factors that are not suitable for the whole sample and for each of the countries.
Table 2: Multiple Group Analysis

\begin{tabular}{|l|c|c|}
\hline \multicolumn{2}{|c|}{ Model 1 } & Model 2 \\
\hline$\chi 2$ & 970,8 & 528,5 \\
\hline Df & 278 & 194 \\
\hline $\mathrm{p}<$ & 0,00 & 0,00 \\
\hline GFI & 0,91 & 0,94 \\
\hline AGFI & 0,89 & 0,92 \\
\hline PNFI & 0,86 & 0,74 \\
\hline TLI & 0,86 & 0,91 \\
\hline CFI & 0,87 & 0,92 \\
\hline RMSEA & 0,06 & 0,05 \\
\hline
\end{tabular}

Since Model 1 (containing 7 factors) did not have satisfactory values, six low loadings items were eliminated and after validity analysis and diagnostics, the final VALS Model 2 was formed based on the scale of six factors with matching items. The final model defined the following six factors, which are suitable for profiling the lifestyle clusters in the Region: activity, fashion, practice, tradition, theory and indolence.

Subsequently, we performed invariance tests across samples in line with the literature (e.g., Steenkamp \& Baumgartner, 1998). The results of invariance testing confirmed that configural and metric invariance should not be a problem for this study. However, loose scalar invariance was partly confirmed, and this calls for further research. Therefore, we believe that measurement equivalence exists across samples, and that the items are equally reliable. As such the measures were used for further testing.

Since the goal of the analysis is to identify groups that describe a certain lifestyle, those factors were used to create lifestyle clusters. Hierarchical analysis used average linkage procedure, because of its small within-cluster variations, with Euclidian distance (Everitt 1993; Hair et al. 2006). Using an agglomeration schedule coefficient to show the level of heterogeneity, the solution of 3 clusters proved to be the most sufficient. Nonhierarchical clustering used a $\mathrm{K}$-means procedure since it has an option of engaging initial cluster centers. Furthermore, validation was conducted in three steps: a different nonhierarchical method (with initial seed points), two-step clustering and cross-validation (for each country per se). Analysis revealed the high consistency of each lifestyle factor and clusters and implies that data can be used with statistical validity to explain behavior in the observed region regardless of the time dimension.

Profiling clusters are self explanatory. It is important to identify characteristics which vary substantially between clusters, and can predict that a subject 
Table 3: CFA factor loadings

\begin{tabular}{|c|c|c|c|c|c|c|}
\hline \multirow{2}{*}{ VALS items } & \multicolumn{6}{|c|}{ Factors } \\
\hline & Activity & Fashion & Practice & Tradition & Theory & Indolence \\
\hline I like a lot of excitement in my life & 0,77 & & & & & \\
\hline I am always looking for a thrill & 0,73 & & & & & \\
\hline I often crave excitement & 0,60 & & & & & \\
\hline I like to lead others & 0,64 & & & & & \\
\hline I like trying new things & 0,61 & & & & & \\
\hline I like to dress in the latest fashions & & 0,89 & & & & \\
\hline I follow the latest trends and fashions & & 0,78 & & & & \\
\hline I dress more fashionably than most people & & 0,63 & & & & \\
\hline I want to be considered fashionable & & 0,57 & & & & \\
\hline I like to make things with my hands & & & 0,89 & & & \\
\hline I like making things of wood, metal, or other such material & & & 0,73 & & & \\
\hline I would rather make something than buy it & & & 0,61 & & & \\
\hline Just as religion says, the world literally was created in six days & & & & 0,75 & & \\
\hline The government should encourage prayers in public schools & & & & 0,72 & & \\
\hline There is too much sex on television today & & & & 0,39 & & \\
\hline $\begin{array}{l}\text { A woman's life is fulfilled only if she can provide a happy } \\
\text { home for her family }\end{array}$ & & & & 0,41 & & \\
\hline I am often interested in theories & & & & & 0,52 & \\
\hline I like to learn about art, culture, and history & & & & & 0,51 & \\
\hline $\begin{array}{l}\text { I would like to understand more about how the universe } \\
\text { works }\end{array}$ & & & & & 0,57 & \\
\hline I like outrageous people and things & & & & & 0,44 & \\
\hline I am really interested in only a few things & & & & & & 0,66 \\
\hline $\begin{array}{l}\text { I must admit that my interests are somewhat narrow and } \\
\text { limited }\end{array}$ & & & & & & 0,61 \\
\hline
\end{tabular}

belongs in a certain cluster. Therefore, identification of the demographic, psychographic and other characteristics determines the segments with defined behavior. The six defined factors used to explain the three clusters are defined as follows:

- Activity - "Leaders always available for adventure"

- Fashion - "Trendy people who want to be perceived as fashionable"

- Practice - "Handyman or housewife enjoying do-ityourself products"

- Tradition - "Individuals oriented to family and religion"

- Theory - "Intellectuals interested in everything around them"

- Indolence - "Individuals lacking interest in the world they live in"

Three clusters have been identified for the entire Region:

1. Urban Intellectuals

2. Trendy and Popular

3. Passive Observers

The cluster called Urban Intellectuals is the dominant lifestyle for persons interested in learning, both in a theoretical (value 0.7) and in a practical sense (0.4). They are active (0.4) and they act as participants

Table 4: Clusters' Profiling

\begin{tabular}{|l|c|c|c|c|c|c|c|}
\hline & Indolence & Theory & Tradition & Practice & Fashion & Activity \\
\hline & $-0,68$ & 0,69 & $-0,56$ & 0,42 & $-0,24$ & 0,45 \\
\cline { 2 - 7 } & Lluster "Urban Intellectuals" & Low & High & Low & High & Middle & High \\
\hline \multirow{3}{*}{ Cluster "Trendy and Popular" } & 0,12 & $-0,25$ & 0,63 & $-0,35$ & 0,83 & 0,35 \\
\cline { 2 - 7 } & Middle & Middle & High & Low & High & High \\
\hline \multirow{2}{*}{ Cluster "Passive Observers" } & 0,85 & $-0,74$ & 0,08 & $-0,22$ & $-0,59$ & $-1,05$ \\
\cline { 2 - 7 } & High & Low & Middle & Low & Low L & Low \\
\hline
\end{tabular}


in all activities around them. On the other hand, those persons are not traditional $(-0.6)$ and are not interested in fashion trends (-0.2). The analysis of the demographic data shows that they are highly educated, middle-aged and have higher incomes. Their goals are set high and they are determined to achieve them. Urban Intellectuals are not interested in trends and popular fashion, they do not join fancy mass culture and they are not followers. This cluster is the largest in the region, comprising $41.73 \%$ of respondents.

The cluster called Trendy and Popular gathers individuals who are highly traditional (0.6) and fashionable (0.8). To explain this finding it is necessary to understand the overall situation in the Region. Currently, it is trendy to be religious to an above-average degree, attend all mass gatherings and events, listen to folk music and, for the sake of fashion, purchase counterfeits in order to appear to own a designer label (Husić, Ostapenko 2010). This group is relatively high on indolence (0.1) and uninterested in hand-craft $(-0.3)$, success or achievement. For them it seems easiest to blend into the majority and be popular by following the trend. This group consists mainly of moderately educated, mid-level income women. A total of $32.02 \%$ of respondents are placed in this cluster.

The cluster called Passive Observers is very high in terms of indolence (0.8) and absolutely not interested in life and the world around them (theory -0.7). It was expected that this group would be more traditional (0.1) and religious, but considering their overall lack of interest, they are passive in this area as well. They are mostly men, older than the average sample, with lower education and a lower level of income. Individuals belonging to this group are commonly disappointed and tired. The Passive Observers cluster is the smallest in the Region with $26.25 \%$ of respondents.

The specifics that determine some of the differences between the countries reveal that Bosnia and Herzegovina is overall more traditional than the average in the region, with strong religious beliefs. Croatia has an almost perfect equivalence with the region overall and many similarities with Bosnia and Herzegovina. In Serbia the cluster Trendy and Popular is more dedicated to a contemporary trend of urban living than the average for the region, while at the same time Serbia proves to be the most traditionoriented country. Slovenia differs from the regional average the most in its socio-economic and political development. Therefore, it is not surprising that its population shares somewhat different values from the rest of the region. Generally, it can be concluded that Slovenia is less traditional and more fashionable. However, the same lifestyle patterns can be applied.

Detailed lifestyle analysis confirmed that political, economic and social differences between consumers in Bosnia and Herzegovina, Croatia, Serbia and Slovenia do not imply different lifestyles. This was confirmed by a cluster validity analysis using a different non-hierarchical procedure with initial seed points and a two-step clustering procedure. Finally, demographic analysis of the region showed that three demographic variables have statistically significant differences for all three clusters. Those variables are gender (Chi-square 6.081, significance 0.048), age (Chi-square 22.434, significance 0.004) and education (Chi-square19.929, significance 0.044).

\section{CONCLUSION}

The findings of the study can greatly increase managerial cooperation in the region. For some companies each of the presented countries per se may be an insignificant market, but the region as a whole represents a fairly large segment. This finding has the potential to bring the Region closer in terms of creating a mutual approach to foreign direct investment or even stimulating the growth of regional companies. With markets segmented on the same basis in the four countries, companies can create and promote the same products or services, overcoming the borders between the countries, and approaching the regional market. Modifications would be necessary only in terms of language, while product attributes could remain the same. Moreover, foreign trade offices could use lifestyle similarities in order to obtain foreign investment. Each country per se is not lucrative enough for large investors, but the twenty-million consumers of the entire market would be. Moreover, there is insufficient data on lifestyle analysis in the Western Balkan countries. Hence, marketing managers can have better profiles of their consumers and be in a better position to market their offerings to targeted lifestyle segments.

On the social side, this research shows that economic, political and social differences have less influence on lifestyle than historical and cultural similarities. Knowing that consumers use certain products to accmplish and/or maintain their relationships with others, it can be argued that people in the region still have a common attitude. Current lifestyle unconsciously influences not only the consumers' product or brand choice, but also their needs and attitudes. Those psychographic regional similarities can be used to strengthen common spirit and enhance cooperation, prosperity, and peace in the region. The observed markets were within the same country for 70 years, and the only during the last 20 years did they 
experience different circumstances, development patterns and internal structural forces. Those results indicate that previous development has been stronger than the last twenty years of separation. However, it should be noted that even today Slovenia is the main investor in Serbia and Bosnia and Herzegovina, that Serbia and Croatia are the main trade partners of Bosnia and Herzegovina, and that major brands and companies still have the same business approach in all of the observed countries. It seems that linkages and healthy economic and trade patterns cannot be erased by several decades of separate development.

To conclude, this lifestyle study indicates that a regional collection of countries previously comprising a common state, one that has very similar languages, and shares many cultural traits and traditional economic and political linkages, even while experiencing very different destinies over the last twenty years stills maintain a very similar structure and shared segmentation, while showing only insignificant differences.

As for the limitations of this research, the theory and practice still lacks a complete lifestyle scale that can be applied regardless of cultural context. VALS is the most frequently used methodology (Lin 2002; Todd, Lawson and Faris1996), but it is primarily created for the U.S. market. Considering the importance of the information that lifestyle segmentation provides, it is expected that new scales and methodologies will be developed accordingly.

Finally, this research used a convenience sampling method, which is its main limitation. For better insight into the population, rural areas have to be covered as well, and a larger-scale sample should be used for further explorations.

\section{BIBLIOGRAPHY}

Adler A. 1929. Problems of Neurosis: A Book of Case Histories. Harper Torchbook: 1964. ed. P. Mairet, New York: Harper and Row

Anderson WT, Golden L. 1984. Life-style and psychographics: a critical review and recommendation, Advances in Consumer Research XI. Association for Consumer Research, Ann Arbor, Ml, pp 405-11

Barry J,Weinstein A. 2009. Business psychographics revisited: from segmentation theory to successful marketing practice. Journal of Marketing Management. 25(3-4). pp. 315-340

Bhattacharjee A, Berger J, Menon G. 2014. When Identity Marketing Backfires: Consumer Agency in Identity Expression. Journal of Consumer Research. 41. pp. 294-309
Bootsma H, Camstra R, De Feijter H, Mol A. 1993. Leefstijl: een dyamische levensorientatie. Rooilijn. 8. pp. 332 - 337

Chernev A, Hamilton R, Gal D. 2011. Competing for Consumer Identity: Limits to Self-Expression and the Perils of Lifestyle Branding. Journal of Marketing. 66(75). pp. 66-82

Demby E. 1974. Psychographics and from Where it Came, in W.D. Wells (ed.) Life Style and Psychographics pp. 9-30, Chicago: American Marketing Association

Escalas JE, Bettman JR. 2005. Self-Construal, Reference Groups, and Brand Meaning. Journal of Consumer Research, 32. pp. 378-89

Everitt BS. 1993. Cluster Analysis. 3rd ed. New York: Halsted Press

Featherstone M. 1987. Lifestyle and consumer culture. in Meyer E: Everyday Life, Leisure and Culture. Conference proceedings: Centre for Leisure Studies Tilburg University, pp. 343-354

Feldman SD, Thielbar GW. 1972. Lifestyles: Diversity in American Society. Boston: Little Brown and Co.

Green GT, Gordell HK, Betz GJ, DiStefano G. 2006. Construction and Validation of the National Survey on Recreation and the Environment's Lifestyles Scale. Journal of Leisure Research.34, pp. 513-535

Hair JF, Black W, Babin JB, Anderson RE, Tatham RL. 2006. Multivariante Data Analysis. 6th ed, New Jersey: Prentice Hall

Havighurst RJ, deVries A. 1969. Life Styles and Free Time Activities of Retired Men. Human Development 12 (1), pp. 34-54

Hawkins DI, Best RJ, Coney KA. 1993. Consumer Behavior: Implications for Marketing Strategy. 5th ed., Homewood, IL: Irwin Publishing

Holt D. 1997. Poststructuralist Lifestyle Analysis: Conceptualizing the Social Patterning

of Consumption in Postmodernity. Journal of Consumer Research. Vol. 23, pp. 326-350

Husić M, Ostapenko N. 2010. Celebrating Recession in Style: The Mainstreaming of Attitudes toward Luxury Consumption in the Balkans and European Russia. 2010 Oxford Business and Economics Conference. June 28-30 2010. Oxford. Great Britain

Kahle LR. ed. 1983. Social Values and Social Change: Adaptation to Life in America. New York: Praeger

Levy SJ. 1963. Symbolism and Life Style. in Proceedings, American Marketing Association, Greyser Stephen A. ed. Chicago: American Marketing Association, pp. 140-150

Lin CF. 2002. Segmenting customer brand preference: demographic or psychographic. Journal of Product and Brand Management, Vol. 11 No. 4, pp. 249-268

Miedema S. 1989. Lifestyles of working class youth: leisure and delinquency. in Tomlinson A. Youth Culture and the Domain of Leisure. Vol. 4 Leisure, Labor and Lifestyles, Eastbourne 
Murphy JF. 1974. Leisure determinants of life style. Leisure Today: Selected Readings. American Alliance for Health, Physical Education and Recreation: Washington DC, pp. 9-11

Peltier JW, Scribrowsky JA, Schultz DE, Davis J. 2002. Interactive Psychographics: Cross-Selling in the Banking Industry. Journal of Advertising Research. 3 pp. 7-22

Pronay S, Hetesi E, Veres Z. 2009. Lifestyles and Consumption in a Transitional Society: Psychographic Segmentation in Southern Hungary. Akademija MM. pp. 41-51 Reed A, Forehand MR, Puntoni S, Warlop L. 2012. Identity-Based Consumer Behavior. International Journal of Research in Marketing. 29 (4). pp. 310-21

Reece G. 1989. Psycho-selling. Channels. 8. pp. 14-16

Richards EA, Sturman SS. 1977. Life-style Segmentation in Apparel Marketing. Journal of Marketing. 10. pp. 89-91

Ruiz JI. 1990. Life styles and daily leisure - (Victoria's Case). In Sociology, Czechoslovak Academy of Science, 2 Volume. pp. $156-169$

Scheys M. 1986. The power of life style. Paper to the XIth World Congress of Sociology, New Delhi, Aug 18-22; also in Society and Leisure, 10(2), pp. 249-266

Schutz HG, Baird PC, Hawke GR. 1979. Lifestyles and Consumer Behavior of Older Americans. Praeger: New York

Shih D. 1986. VALS as a tool of tourism market research: The Pennsylvania experience. Journal of Travel Research. 4. pp. 2-11
Sobel ME. 1983. Lifestyle differentiation and stratification in contemporary US society. in Treiman DJ, Robinson RV (eds.): Research in social stratification and mobility, Vol. 2

SRI Consulting Business Intelligence. 2006. Understanding U.S. Consumers. April 2006

Steenkamp, J. B. E., Baumgartner, H. 1998. Assessing measurement invariance in cross-national consumer research. Journal of consumer research, 25(1), pp. 78-107

Stokburger-Sauer N, Ratneshwar S, Sen S. 2012. Drivers of Consumer-Brand Identification. International Journal of Research in Marketing. 29 (4). pp. 406-18

Todd S, Lawson R, Faris F. 1996. A Lifestyle Analysis of New Zealand Consumers. In A. Martin and R. Starr (Eds.), Proceedings of the Australia New Zealand Marketing Educators Conference. Auckland, New Zealand: University of Auckland. pp.328-347

Todd S, Lawson R. 2001. Lifestyle segmentation and museum/gallery visiting behaviour. International Journal of Nonprofit and Voluntary Sector Marketing. 3, pp. 269-277

Tokarski W. 1987. Leisure and life-style of the elderly: outline of a research program. European Journal of Education, Vol. 22 No. 3/4, pp. 327-333

Wind J, Green R. 1974. Some conceptual, measurement, and analytical problems of life style research. In Life Style and Psychographics, Wells WD. ed. Chicago: American Marketing Association. pp. 99-126

Zablocki B, Kantor R. 1976. The differentiation of lifestyles. Annual Review of Sociology. Palo Alto, Calif: Annual Reviews Inc., pp. 269-298 